\title{
Perancangan Ulang Warp Beam Trolley Menggunakan Ergonomic Function Deployment
}

\author{
Eko Kurniawan *1, Hari Purnomo ${ }^{2}$ \\ ${ }^{1,2}$ Program Studi Teknik Industri, Fakultas Teknologi Industri, Universitas Islam Indonesia \\ Jalan Kaliurang Km. 14,5 Sleman, Yogyakarta, 55584, Indonesia \\ Email: kurniawan.eko4@gmail.com¹ ${ }^{1}$, haripurnomo@uii.ac.id²
}

\begin{abstract}
Abstrak
Kegiatan memindahkan benda berat secara manual menggunakan alat bantu dimaksudkan untuk memudahkan dan meringankan beban kerja tubuh manusia. Unit Produksi Pertenunan di Bengkel Teknik Pembuatan Kain SMK Negeri 3 Kota Pekalongan saat ini menggunakan kereta lalatan (Beam trolley) sebagai alat transportasi gulungan benang lusi (warp beam). Beam trolley yang ada sulit dikendalikan ketika didorong dan kurang nyaman saat digunakan bahkan dapat menyebabkan permukaan gulungan benang rusak atau kotor. Tujuan penelitian ini menghasilkan rancangan Beam trolley untuk pemindahan warp beam yang ergonomis, aman dan tidak menyebabkan turunnya kualitas gulungan benang. Metode perancangan menggunakan Ergonomic Function Deployment (EFD). Hasil penelitian menggunakan metode EFD berupa prototype Beam trolley dengan spesifikasi sebagai berikut: (1) dimensi Beam trolley $190 \mathrm{~cm}$ x 60 $\mathrm{cm}$ yang disesuaikan dengan antropometri pengguna; (2) pegangan dengan jarak $155 \mathrm{~cm}$, lebar $34 \mathrm{~cm}$, diameter $4 \mathrm{~cm}$ dan tinggi $100 \mathrm{~cm}$. Pegangan berfungsi sebagai penarik atau pendorong. Prototype Beam trolley dilengkapi empat roda dinamis untuk fleksibilitas arah gerakan yang dilengkapi pengunci roda dan memiliki alat untuk mengangkat dan menurunkan beban.
\end{abstract}

Kata kunci: Beam trolley, Perancangan, Tekstil, Antropometri, Ergonomic Function Deployment

\begin{abstract}
Activities to move heavy objects manually using tools to facilitate and lighten the workload of the human body. The Weaving Production Unit at the Fabric Making Engineering Workshop at SMK Negeri 3 Pekalongan City, uses a beam trolley as a means of transporting warp beam. The beam trolley, which is difficult to control when turning and uncomfortable to use, can even cause the yarn winding surface to be damaged or dirty. The purpose of this research is to produce a beam trolley design for ergonomic, safe transfer of warp beams and does not cause a decrease in quality of the yarn spools. The design method using Ergonomic Function Deployment (EFD). The results of the study used the EFD method in the form of a Beam trolley prototype with the following specifications: (1) Beam trolley dimensions $190 \mathrm{~cm} \times 60 \mathrm{~cm}$ adjusted to the user's anthropometry; (2) handles $155 \mathrm{~cm}$ apart, $34 \mathrm{~cm}$ wide, $4 \mathrm{~cm}$ in diameter and 100 $\mathrm{cm}$ high. The handle serves as a pull or push. The prototype Beam trolley is equipped with four dynamic wheels for flexibility in the direction of movement which is equipped with wheel locks and has a tool to lower and lower the load.
\end{abstract}

Keywords: Beam trolley, Design, Textiles, Anthropometry, Ergonomic Function Deployment

\section{Pendahuluan}

Pekerjaan yang dilakukan secara manual merupakan pekerjaan yang melibatkan kegiatan mengangkat, menurunkan, mendorong, menarik, dan membawa sesuatu (Ayoub \& Dempsey, 1999). Pekerjaan yang bersifat manual jika tidak dilakukan secara ergonomis akan menimbulkan keluhan kerja hingga kecelakaan kerja (Nurmianto, 2006). Jika pekerjaan berat dilakukan secara terus menerus, maka akan menimbulkan gangguan pada tubuh manusia dan berdampak buruk pada kondisi kesehatan (Suma'mur, 1995). Begitu juga yang terjadi di Unit Produksi Pertenunan, SMK Negeri 3 Kota Pekalongan yang sebagian besar pekerjaan dilakukan secara manual. Penanganan warp beam yang meliputi pekerjaan menurunkan, transportasi, dan pekerjaan menaikan menggunakan Beam trolley. Pekerjaan tersebut merupakan proses pembelajaran praktik bagi siswa SMK Negeri 3 Kota Pekalongan.

Pengamatan awal dilakukan dengan observasi langsung dan wawancara dengan 4 instruktur praktik dan siswa. Observasi langsung menunjukkan bahwa proses penanganan warp beam dilakukan tidak ergonomis dikarenakan alat yang digunakan belum dirancang sesuai dengan tubuh siswa. Hasil wawancara diidentifikasi bahwa Beam trolley yang ada mempunyai beberapa kekurangan antara lain: (1) tidak memiliki pegangan untuk mendorong; (2) ukuran lebih pendek dari warp beam; (3) sulit dikendalikan saat didorong untuk membawa warp beam; (4) membutuhkan tenaga yang

${ }^{*}$ Penulis utama (Corresponding author) 
besar saat menaikan dan menurunkan warp beam ke Beam trolley; dan, (5) resiko kerusakan permukaan gulungan benang. Berdasarkan hasil pengamatan awal perlu dilakukan perbaikan Beam trolley sesuai dengan tubuh siswa. Hal ini dikarenakan dimensi alat mengalami interaksi langsung dengan tubuh manusia (Heni et al., 2017).

Penelitian ini menggunakan metode EFD untuk mendesain ulang Beam trolley yang ergonomis dan aman untuk bahan baku. EFD merupakan metode untuk memudahkan proses perancangan dimana pembuatan keputusan direkam dalam bentuk matriks-matriks sehingga dapat diperiksa ulang serta dimodifikasi dimasa yang akan datang (Suriadi \& Atmika, 2017). Penggunaan metode EFD bertujuan untuk menghasilkan perancangan produk alat bantu yang ergonomis dan sesuai kebutuhan pengguna (Anwardi et al., 2019). Perancangan alat tersebut diperlukan data antropometri untuk menyesuaikan dimensi alat dengan dimensi tubuh pengguna agar didapat alat bantu yang ergonomis (Setiadi et al., 2013; Hidayat et al., 2013). Beberapa penelitian terkait dengan penggunaan metode EFD telah dilakuan. Penelitian Liansari et al., (2016) merancang alat cetak kue balok untuk mengurangi resiko cidera. Perancangan ulang kursi penumpang kereta ekonomi yang ergonomis dengan hasil rancangan dengan nilai dan fungsi lebih baik (Puspitasari \& Wibowo, 2016). Pada penelitian ini, diharapkan rancangan Beam trolley yang ergonomis dan sesuai dengan kebutuhan dapat memberikan rasa aman bagi pengguna.

\section{Metode Penelitian}

\subsection{Subjek dan Objek Penelitian}

Objek penelitian adalah merancang ulang Beam trolley yang ergonomis, untuk digunakan pada praktik pemindahan dan pemasangan warp beam. Lokasi penelitian dilakukan di Unit Produksi Pertenunan SMK Negeri 3 Kota Pekalongan. Subjek pada penelitian ini terdiri dari instruktur dan siswa praktik jurusan Teknik Pembuatan Kain SMK Negeri 3 Pekalongan sejumlah 30 orang. Kriteria inklusi subjek adalah: (1) Instruktur berusia 30-58 tahun; (2) pengalaman instruktur minimal satu tahun; (3) siswa berusia 16-20 tahun; (4) instruktur dan siswa dalam kondisi sehat dan tidak cacat fisik.

\subsection{Metode Pengumpulan Data}

Metode pengumpulan data dilakukan dengan observasi langsung, wawancara dan pengukuran langsung dilapangan.

a. Observasi dilakukan dengan pengamatan langsung proses penggunaan Beam trolley. Dalam hal ini dilakukan pengamatan proses pengangkatan, pemindahan dan penurunan warp beam.

b. Wawancara dilakukan kepada instruktur dan siswa. Materi wawancara terkait dengan penggunaan alat, kesulitan yang dialami dalam menggunkan alat, tenaga yang diperlukan pada saat mengoperasikan alat dan tingkat kerusakan warp beam.

c. Pengukuran langsung dilakukan dengan mengukur dimensi alat lama yaitu tinggi alat, panjang alat, lebar alat dan tinggi roda. Disamping pengukuran alat, juga dilakukan pengukuran dimensi tubuh pengguna yang digunakan untuk menentukan dimensi alat baru.

\subsection{Prosedur Penelitian}

Prosedur penelitian merupakan tahapan-tahapan penelitian dari tahap persiapan sampai tahap analisis. Prosedur penelitian dapat dijelaskan sebagai berikut:

a. Tahap Persiapan.

Pada tahap ini dilakukan persiapan penelitian dengan langkah-langkah antara lain: (1) menyiapan subjek penelitian dengan memilih instruktur dan siswa yang memenuhi kriteria inklusi; (2) menyiapkan alat yang digunakan untuk penelitian seperti meteran atau alat ukur, kuesioner yang digunakan untuk wawancara, alat lama yang akan diukur; (3) siswa yang akan diukur dimensi tubuh; (4) alat untuk mengukur dimensi tubuh.

b. Tahap Perancangan.

Pada tahap ini dilakukan perancangan menggunakan EFD. EFD merupakan pengembangan dari Quality Function Deployment (QFD) dengan menambahkan hubungan baru antara keinginan konsumen dan aspek ergonomi sebuah produk (Ulrich \& Eppinger, 2001). Hubungan ini akan melengkapi bentuk matrik House of Ergonomic yang juga diterjemahkan ke dalam aspek-aspek ergonomi yang diinginkan (Surya et al., 2015).

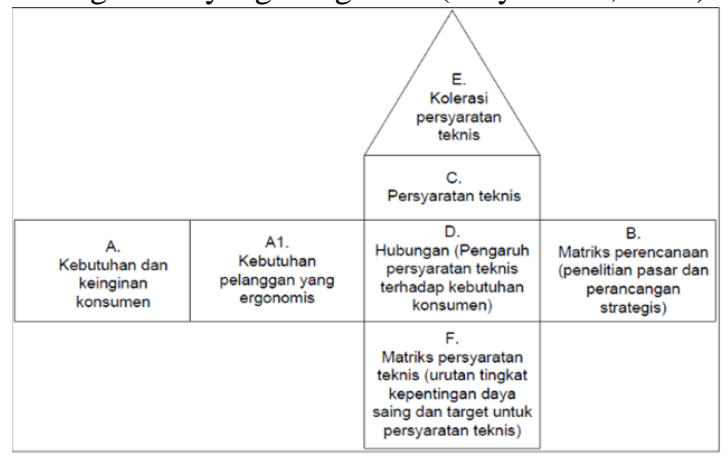

Gambar 1. House of Ergonomic

Langkah-langkah yang dilakukan dalam perancangan menggunkan EFD sebagai berikut: (1) identifikasi kebutuhan pengguna; (2) membuat matriks perencanaan yang digunakan untuk menentukan prioritas pemenuhan kebutuhan konsumen, yang terdiri dari tingkat importance of costumer, pengukuran tingkat kepuasan pengguna terhadap produk, nilai target (goal), improvement ratio, sales point dan, raw weight; (3) spesifikasi teknik produk (technical 
response); (4) relationship; (5) technical corelation; (6) technical matrix; dan (7) perancangan.

c. Tahap Analisis.

Pada tahap ini dilakukan analisis dari hasil penelitian atau hasil rancangan yang bertujuan untuk mengetahui kesesuaian rancangan Beam trolley dengan kebutuhan pengguna.

\section{Hasil dan Pembahasan}

\subsection{Identifikasi Kebutuhan}

Responden yang dipilih untuk mengisi kuisioner tingkat kepuasan dan kepentingan penggunaan Beam trolley adalah siswa peserta praktikum dan instruktur di Unit Produksi Pertenunan SMK Negeri 3 Kota Pekalongan. Jumlah responden yang dilibatkan dalam penelitian ini adalah 30 responden. Penyebaran kuisioner dan wawancara dengan responden bertujuan agar responden tersebut dapat memberikan pendapat berkaitan dengan tingkat kepuasan penggunaan Beam trolley yang ada dan harapan pada penggunaan Beam trolley yang diusulkan.

Berdasarkan data responden yang dikumpulkan, responden dengan jenis kelamin laki-laki sebanyak 26
$(43,33 \%)$ dan sebanyak 34 orang perempuan $(56,67 \%)$. Beam trolley lama yang digunakan di Unit Produksi Pertenunan SMK Negeri 3 Kota Pekalongan ditunjukkan pada Gambar 2.

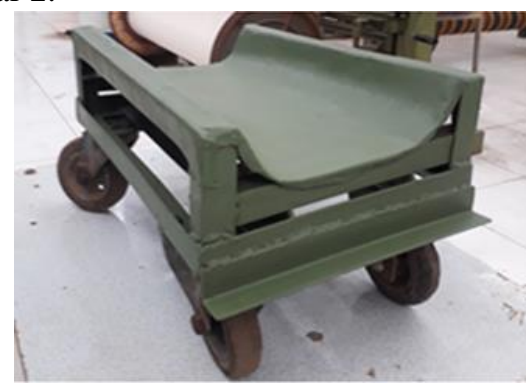

Gambar 2. Beam trolley lama

Proses pengumpulan kebutuhan konsumen dilakukan dengan menyebarkan kuisioner dan wawancara. Perancangan suatu produk mengikuti aspek Efektif, Nyaman, Aman, Sehat, Efisien (El Ahmady et al., 2020). Berdasarkan aspek ini, dibentuk kebutuhan konsumen yang didasarkan pada perbaikan produk baru. Pembentukan kebutuhan ergonomis untuk memenuhi aspek keamanan dan keselamatan pengguna produk baru.

Tabel 1. Kebutuhan Konsumen

\begin{tabular}{|c|c|c|}
\hline Aspek ENASE & Kebutuhan Konsumen & Kebutuhan Ergonomis \\
\hline Efektif & Fungsional & $\begin{array}{l}\text { Beam trolley mudah dioperasikan } \\
\text { Beam trolley dilengkapi pegangan } \\
\text { pendorong/ penarik } \\
\text { Beam trolley dilengkapi alat pengangkat } \\
\text { Beam trolley dapat bergerak maju dan } \\
\text { menyamping }\end{array}$ \\
\hline Nyaman & Ukuran & $\begin{array}{l}\text { Dimensi Beam trolley sesuai dengan } \\
\text { konstruksi mesin produksi } \\
\text { Dimensi Beam trolley sesuai dengan } \\
\text { antropometri operator }\end{array}$ \\
\hline Aman & Resiko kerja & $\begin{array}{l}\text { Beam trolley dapat mengurangi beban } \\
\text { tenaga operator }\end{array}$ \\
\hline Sehat & $\begin{array}{l}\text { Bahan material } \\
\text { Ekonomis }\end{array}$ & $\begin{array}{l}\text { Beam trolley tidak mencederai operator } \\
\text { Harga Beam trolley terjangkau }\end{array}$ \\
\hline Efisien & $\begin{array}{l}\text { Perawatan } \\
\text { Bahan Baku }\end{array}$ & $\begin{array}{l}\text { Beam trolley mudah perawatannya } \\
\text { Bahan kuat dan awet }\end{array}$ \\
\hline
\end{tabular}

\subsection{Pembentukan House of Ergonomic}

HOE merupakan kompilasi dari seluruh analisis pada metode EFD. Pada bagian ini, dilakukan identifikasi kebutuhan konsumen, analisis aspek teknis, penghubungan variabel, benchmark dan penentuan prioritas kebutuhan rancangan. Hasil HOE ditunjukkan seperti pada Gambar 3. 


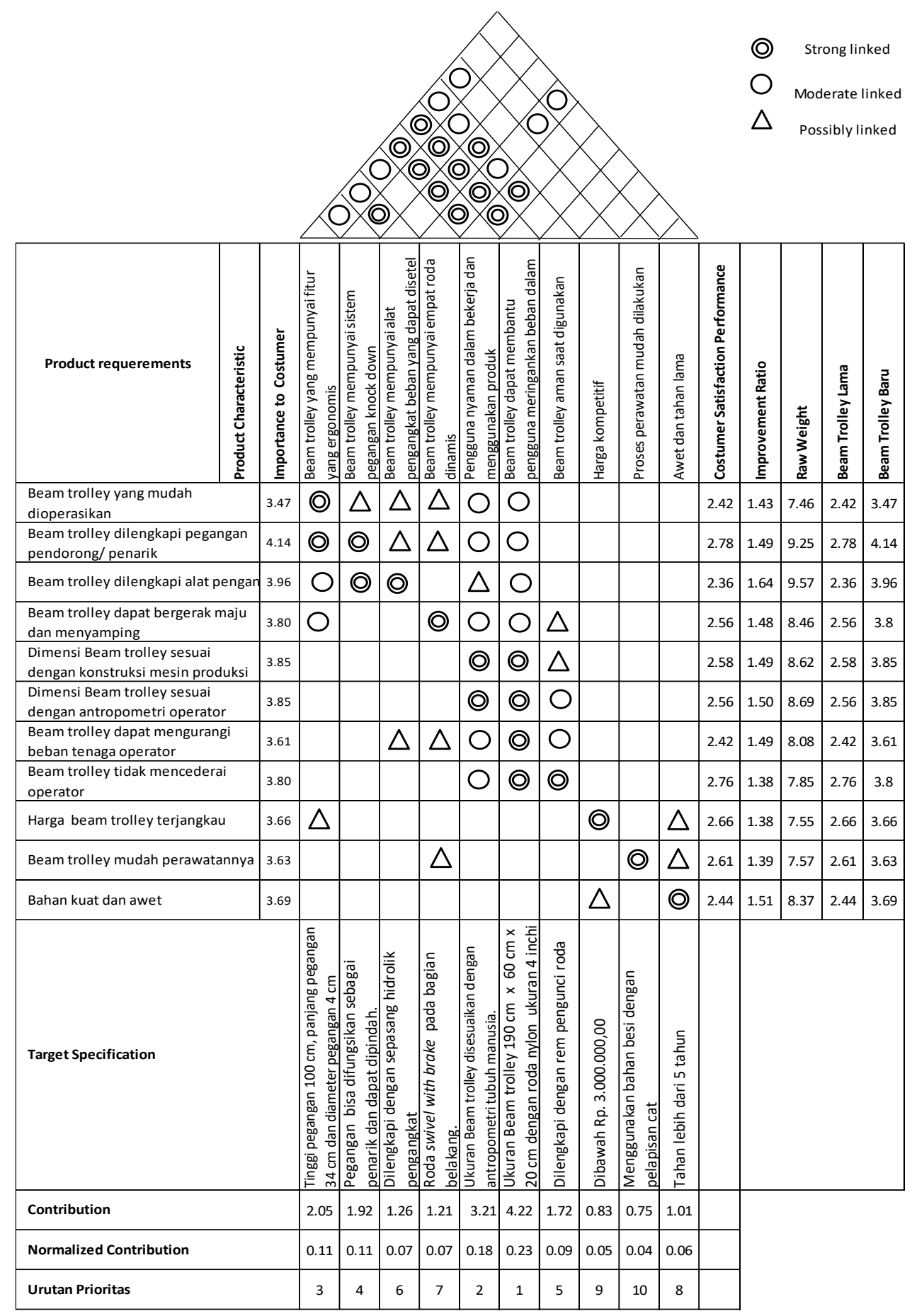

Gambar 3. House of Ergonomic

Pada Gambar 3, merupakan hasil HOE yang dapat dijelaskan sebagai berikut:

a. Nilai tingkat kepentingan konsumen (important to costumer) atau nilai goal ditetapkan untuk menentukan sasaran yang akan dicapai. Pada aspek ini digunakan untuk memenuhi kebutuhan konsumen. Nilai tingkat kepentingan menggunakan skala 1 sampai 5. Nilai tingkat kepentingan konsumen tertinggi sebesar 4,14 yang berarti prioritas pertama Beam trolley dilengkapi dengan pegangan pendorong dan penarik. Sedangkan nilai terendah sebesar 3,47 yaitu Beam trolley mudah dioperasikan.

b. Tingkat kepuasan konsumen (costumer satisfaction performance) merupakan tanggapan terhadap produk yang dapat memenuhi kebutuhan konsumen. Pernyataan yang diberikan adalah kesesuaian harapan konsumen.

c. Rasio perbaikan (improvement ratio) akan menunjukan seberapa besar usaha yang harus dilakukan perusahaan untuk mencapai goal. Nilai yang semakin besar akan menunjukan 
semakin besar tingkat perubahan yang harus dilakukan. Nilai tertinggi sebesar 1,64 terdapat pada variabel Beam trolley dilengkapi alat pengangkat. Sedangkan nilai terendah sebesar 1,38 terdapat pada variabel Beam trolley mempunyai harga yang terjangkau.

d. Titik jual (sales point) menunjukan seberapa besar pengaruh dalam memenuhi permintaan konsumen terhadap produk. Penetapan titik jual ditetapkan berdasarkan pada nilai tingkat kepentingan. Pada penelitian ini digunakan nilai 1,5 (strong sales point) karena rancangan mempunyai nilai tambah yang tinggi terhadap produk.

e. Nilai raw weight adalah nilai tingkat kepentingan secara menyeluruh dari kebutuhan konsumen. Besarnya nilai raw weight diperoleh dari perkalian antara tingkat kepentingan, rasio perbaikan dan sales point. Semakin besar nilai raw weight yang didapatkan semakin penting kebutuhan tersebut untuk segera dipenuhi.

f. Respon teknis berisi tentang kebutuhan konsumen dalam bentuk istilah teknis. Respon teknis menunjukkan rencana rancangan dalam mewujudkan kebutuhan konsumen tersebut. Hubungan antara respon teknis dan kebutuhan konsumen atau pengguna dapat ditunjukkan dengan simbol yang melambangkan seberapa kuat hubungan antara respon teknis dan kebutuhan konsumen atau pengguna. Semakin banyak simbol suatu elemen pada karakteristik teknis dengan kebutuhan konsumen, maka elemen-elemen karakteristik teknis tersebut berpengaruh dalam pemenuhan kebutuhan konsumen atau pengguna.

g. Target spesifikasi merupakan suatu hasil yang dikembangkan dari pengembangan karakteristik teknis yang didapat dari identifikasi kebutuhan konsumen.

h. Benchmarking adalah salah satu kegiatan yang akan dilakukan untuk melakukan perbandingan yang sistematis terhadap proses dan kinerja. Tujuan benchmarking untuk menciptakan standar baru atau meningkatkan proses. Pada penelititan ini, produk yang sudah ada di Unit Produksi Pertenunan SMK Negeri 3 Kota Pekalongan dipilih sebagai pembanding. Hasil perbandingan produk lama dan rancangan produk baru ditunjukkan pada Gambar 4 .

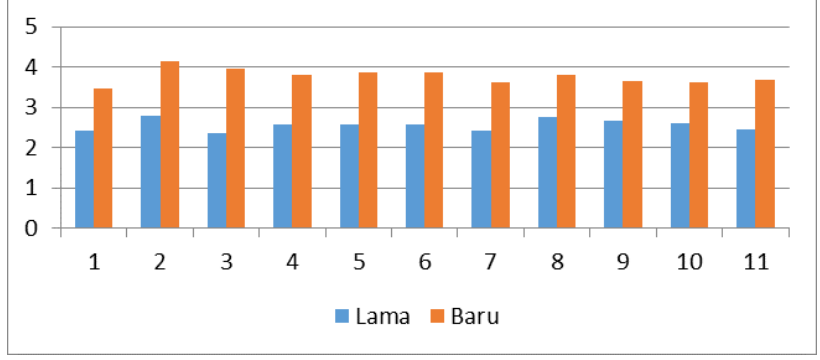

Gambar 4. Benchmarking produk

\subsection{Perancangan Beam trolley}

Hasil EFD didapat rancangan Beam trolley seperti pada Gambar 6, yang merupakan perbaikan dari Beam trolley yang lama Gambar 5.

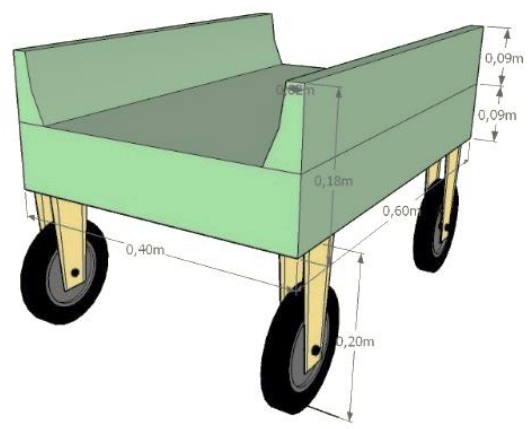

Gambar 5. Beam trolley terdahulu

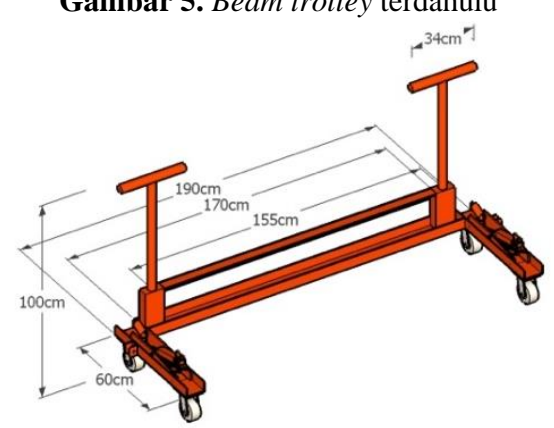

Gambar 6. Beam trolley rancangan

Beam trolley lama memiliki perbedaan dengan Beam trolley rancangan berdasarkan kebutuhan konsumen. Perbedaan tersebut dijelaskan sebagai berikut: (1) Produk lama memiliki dimensi 60 x 40 x 28 $\mathrm{cm}$, lebih pendek dari ukuran warp beam. Dimensi produk baru 190 × 60 × $20 \mathrm{~cm}$ yang menyesuaikan antropometri pengguna. Hasil ini didukung penelitian (Sutalaksana \& Widyanti, 2016) yang menyatakan bahwa kesesuaian dimensi tubuh dengan dimensi mesin produksi dapat memberikan kenyamanan dan keamanan pekerja; (2) Produk lama memiliki 2 roda dinamis dibagian belakang dan 2 roda statis dibagian depan dengan diameter 5 inchi. Produk baru menggunakan 4 roda dinamis dengan diameter 4 inchi, dengan letak roda yang lebih lebar dari warp beam. Hasil ini sesuai dengan pendapat (Zepeda et al., 2017) yang menjelaskan bahwa berat beban yang terdistribusi merata pada Beam trolley dapat mengurangi gaya gesek dengan lantai; (3) Produk lama tidak dilengkapi pegangan. Produk baru dilengkapi pegangan yang bisa dipindah posisi sesuai arah jalan kereta dan berfungsi juga sebagai pendorong atau penarik. Tinggi pegangan berpengaruh pada penggunaan 
tenaga operator saat mendorong Beam trolley (Culvenor, 2005); (4) Produk lama tidak memiliki alat pengangkat, pada produk baru dilengkapi sistem hidrolik untuk mengangkat dan menurunkan beban. Sistem hidrolik memperpendek waktu penanganan material dan aman bagi pekerja (Gujar et al., 2010).

\section{Kesimpulan}

Hasil penelitian rancangan Beam tolley menggunakan metode EFD didapatkan karakteristik teknis sebagai terjemahan dari voice of costumer yang kemudian dijadikan dasar untuk menentukan target spesifikasi produk. Berdasarkan prioritas hasil perhitungan didapat dimensi Beam trolley $190 \mathrm{~cm}$ x 60 $\mathrm{cm}$ yang dilengkapi pegangan dengan tinggi $100 \mathrm{~cm}$ dan lebar $34 \mathrm{~cm}$. Pegangan menggunakan pipa besi diameter $4 \mathrm{~cm}$ dengan jarak antar pegangan $155 \mathrm{~cm}$ sesuai dengan antropometri pekerja. Pegangan dengan sistem knock down dapat difungsikan sebagai penarik. Beam trolley dilengkapi hidrolik untuk mengangkat dan menurunkan warp beam dengan tumpuan pada poros beam sehingga aman untuk permukaan gulungan benang. Roda menggunakan jenis caster swivel sebanyak 4 buah, dengan 2 roda pada sisi samping dilengkapi rem pengunci untuk keamanan. Beam trolley menggunakan rangka besi yang dilapisi dengan cat anti karat.

Bagian kesimpulan harus dapat menjawab tujuan penelitian. Jelaskan hasil-hasil penting yang didapatkan yang terkait dengan tujuan penelitian. Selain itu, bagian ini juga menjelaskan keterbatasan penelitian yang dilakukan dan gagasan penelitian berikutnya. Bagian ini ditulis dalam bentuk paragraf dan tidak diperbolehkan ditulis dalam poin-poin.

\section{Daftar Pustaka}

Daftar pustaka disusun menurut abjad dan diketik satu spasi. Gunakan referensi primer, seperti jurnal, prosiding atau buku, untuk memperkaya bagian daftar pustaka. Pastikan bahwa setiap pustaka yang ditulis di daftar pustaka harus disitasi dalam artikel. Format penulisan daftar pustaka menggunakan gaya penulisan (style) APA edisi ke-6. Disarankan menggunakan fasilitas pengelolaan referensi yang disediakan oleh aplikasi EndNote, Mendeley atau Microsoft Word. Contoh-contoh penulisan pustaka sebagai berikut.

Anwardi, M.I., Harpito, Mas'ari, A. (2019). Perancangan Alat Bantu Memanen Karet Ergonomis Guna Mengurangi Resiko Musculoskeletal Disorder Menggunakan Metode RULA dan EFD, Jurnal Hasil Penelitian dan Karya Ilmiah dalam Bidang Teknik Industri. Vol. 5, No. 2, hal. 139-147.

Ayoub M.M. and Demsey P., G. (1999). The Psychophysical Approach to Manual Materials Handlingtask Design, Department of Industrial Engineering, Texas Tech University, Lubbock, Texas USA.
Culvenor, J. (2005). Initial force and desirable handle height range when pushing a trolley. Journal of Occupational Health and Safety - Australia and New Zealand, Vol. 21, No. 4, pp. 341-349.

El Ahmady, F.R., Martini, S., Kusnayat, A. (2020). Penerapan Metode Ergonomic Function Deployment Dalam Perancangan Alat Bantu Untuk Menurunkan Balok Kayu. JISI: Jurnal Integrasi Sistem Industri: Vol. 7, No.1, hal. 21-30.

Gujar, R. P., Arole, A. A., Barhate, K. H., Gawande, S. H., \& Viroff, M. (2010). Design and Development of Attachment for Hydraulic Stacker. International Journal of Engineering Science and Technology, Vol. 2, No. 5, pp. 796-801.

Heni, I.P., Kusnayat, A., Rahayu, M., (2017). Analisis dan Perbaikan Rancangan Material Handling Equipment Aktivitas Pemindahan Kayu Menggunakan Pendekatan Ergonomic Function Deployment Pada PT. Perkebunan Nusantara VIII. e-Proceeding of Engineering: Vol. 4, No. 2, hal. 2396-2402.

Hidayat, R. Huda, L.N., Poerwanto, (2013). Analisis Perancangan Alat Bantu Kerja Operator Angkut di Stasiun Pemanenan pada PT Perkebunan X. eJurnal Teknik Industri FT USU, Vol 4, No. 1, hal. 25-32.

Liansari, G.P., Novirani, D., Subagja, R.N. (2016). Rancangan Blueprint Alat Cetak Kue Balok yang Ergonomis dengan Metode Ergonomic Function Deployment (EFD). Jurnal Rekayasa Sistem Industri, Vol. 5, No.2, hal. 106-117.

Nurmianto, E. (2006). Ergonomi, Konsep Dasar dan Aplikasinya, Guna Widya Jakarta.

Puspitasari, I., Wibowo, R. K. K. (2016). Modifikasi kursi penumpang kereta api ekonomi yang ergonomis dengan metode Ergonomic Function Deployment (studi kasus pada KA. Logawa yang diproduksi di PT. INKA. Jurnal ROTOR, Vol. 9, No. 1, hal. 29-34.

Setiadi, M.Y., Poerwanto, Anizar, (2013). Usulan Alat Bantu Pemindahan Batako Untuk Mengurangi Risiko Musculoskeletal Disorders di PT. XYZ. eJurnal Teknik Industri FT USU, Vol 1, No.3, hal. 37-43.

Suma'mur P. K, (1995). Higene Perusahaan dan Kesehatan Kerja. Gunung Agung, Jakarta

Suriadi, I., Atmika, I.K.A. (2017). Studi Kenyamanan Kursi Penumpang Mini Bus Angkutan Pariwisata di Bali dengan Analisis Ergonomic Function Deployment. Prosiding Konferensi Nasional Engineering Perhotelan VIII - 201, hal. 165-168.

Surya, R.Z., Badrudin, R., Gasali, M. (2015). Aplikasi Ergonomic Function Deployment (EFD) pada Redesign Alat Parut Kelapa untuk Ibu Rumah Tangga, Jurnal Optimasi Sistem Industri, Vol. 13, No. 2, hal. 771-779. 
Sutalaksana, I. Z., \& Widyanti, A. (2016). Anthropometry approach in workplace redesign in Indonesian Sundanese roof tile industries. International Journal of Industrial Ergonomics. Vol. 53, pp. 299-305.

Ulrich, K., \& Eppinger, S. (2001). Perancangan dan Pengembangan Produk, Salemba Teknika.

Zepeda, R., Chan, F., Sawatzky, B. (2016). The effect of caster wheel diameter and mass distribution on drag forces in manual wheelchairs. Journal of Rehabilitation Research \& Development, Vol. 53, No. 6, pp. 893-900. 
Halaman kosong 